\title{
PROJECT REPORT \\ Delivering free healthcare to rural Central Appalachia population: the case of the Health Wagon
}

\author{
T Gardner', P Gavaza ${ }^{2}$, P Meade ${ }^{1}$, DM Adkins ${ }^{2}$ \\ ${ }^{1}$ The Health Wagon, Clintwood, Virginia, USA \\ ${ }^{2}$ Appalachian College of Pharmacy, Oakwood, Virginia, USA \\ Submitted: 20 December 2011; Published: 20 March 2012 \\ Gardner T, Gavaza P, Meade P, Adkins DM \\ Delivering free healthcare to rural Central Appalachia population: the case of the Health Wagon
} Rural and Remote Health 12: 2035. (Online) 2012

Available: http://www.rrh.org.au

A B S T R A C T

Central Appalachia residents present unique healthcare challenges. This vulnerable population faces poor health status and low access to health care. 'The Health Wagon' was established to innovatively enhance access to health care for the poor and marginalized rural population of Central Appalachia. This article describes the operations of the Health Wagon, a full mobile medical clinic, in delivering free health care to those in rural Southwest Virginia in Central Appalachia. The Health Wagon provides a wide range of comprehensive healthcare services, such as acute and chronic disease management, laboratory and diagnostic services, medication assistance, dental and eye care and specialty clinics for marginalized, poor and disenfranchised patients living in the mountains of that region. In 2009, a total of 157 clinics were provided and 2900 patients were seen (3165 patient encounters) in addition to 268 telemedicine specialty consultations at no cost to the patients. The work of the Health Wagon has broken down a financial barrier to healthcare access and offers unique and profound opportunities to improve health and expand health care in rural Central Appalachia.

Key words: access barriers, Appalachia, free health care, USA. 


\section{Introduction}

Access to health care is a significant issue in American society ${ }^{1}$. Health outcomes are directly related to access to healthcare ${ }^{2,3}$; however, different US population groups have differential healthcare access, according to minority versus non-minority status, severity of illness/disease, race, ethnicity, socioeconomic status, and geographic (rural vs urban) location ${ }^{3}$. A large and growing section of society is unable to obtain quality healthcare services $^{1,4}$. This is especially so in Southwest Virginia in Central Appalachia, where many people lack access to medical care due to a number of factors.

This article describes the access to care issues of the population living in Southwest Virginia in Central Appalachia, and the innovative approach of the Health Wagon designed to address the problem of access to health care.

\section{Background and health disparities in Southwest Virginia in Central Appalachia}

The Appalachian Region stretches from southern New York to northeastern Mississippi, a distance of more than $1609 \mathrm{~km}$ (1000 miles), covering $329916 \mathrm{~km}^{2}$ (205 000 miles $^{2}$ ) across 420 counties $^{5}$. The region includes parts of Virginia, Kentucky, Tennessee, South Caroline, Alabama, Georgia, Maryland, Ohio, Pennsylvania, North Carolina, New York, Mississippi and all of West Virginia - a total of 13 states. The Appalachian Regional Commission divides the region into five sub-regions: Northern Appalachia, North Central Appalachia, Central Appalachia, South Central Appalachia, and Southern Appalachia, based on economic and demographic characteristics. This report concerns Southwest Virginia in Central Appalachia where the Health Wagon operates.

The Southwest Virginia population is poorer than the rest of the nation and the poverty rate is higher than state (Virginia) average. In 2008, 24\% of the Central Appalachian residents were poor ${ }^{5}$. Most people are unemployed, and unemployment rates are higher than state and national averages ${ }^{5}$. The Appalachian residents have lower educational attainment than the rest of the state ${ }^{6}$, and relatively more people over the age of 25 years do not have a high school diploma compared with the state average.

Southwest Virginia residents have poorer health outcomes compared with the rest of the state and nation ${ }^{5}$. Many people in Southwest Virginia smoke tobacco and are obese than the rest of the state $^{7}$. Data from the Virginia Behavioral Risk Factor Surveillance System show that from $32.4 \%$ to $34.7 \%$ of the adults in Buchanan, Dickenson, and Wise counties are obese. Appalachian residents have higher rates of heart disease, diabetes, and cancer than the state and national averages ${ }^{5,8}$. The Centers for Disease Control found that cancer (lung, cervical and colorectal) death rates in rural Appalachia (176.3 per 100000 population) and all of Appalachia (173.1 per 100000 population) in the period 1994-1998 were much higher than the national average in the same time period ${ }^{9}$.

Many Central Appalachia residents lack access to health care owing to factors such as lack of specialist services, long distances to travel in order to access services, limited public transportation, lack of health insurance, cost, and shortages of healthcare professionals ${ }^{\mathbf{1 0}}$. The Central Appalachia region has a shortage of healthcare professionals and specialist services such as dentistry, mental health services and obstetrics services.

\section{The Health Wagon}

The Health Wagon (www.thehealthwagon.org) was founded in 1980 to provide free health care to medically under-served people in the mountains of Southwest Virginia in Central Appalachia. The Health Wagon operates a mobile health clinic and a walk-in clinic from a fixed location to deliver care to residents of Buchanan, Dickenson and Wise counties. The Health Wagon provides comprehensive primary healthcare services that emphasize education and prevention free of charge to patients (although donations are encouraged and accepted). The Health Wagon also provides diabetic supplies and prescription medications through the state sponsored Pharmacy Connect Program at no cost to patients. The 
Health Wagon coordinates Wise Remote Area Medical which is the largest free outreach of its kind in America.

The work of the Health Wagon has been covered by several national and international media organizations such as AARP Magazine, Time Magazine Online, BBC, National Public Radio, Paris Match, Zuma Press, Associated Press, Reuters, and CNN. In addition, the Health Wagon and its executive director have been recognized by several awards: 2009 AANP Nurse Practitioner State Award for Excellence, 2008 Kid's Central Community Service award, 2007 Virginia Governor's Nonprofit Outstanding Nonprofit Award, 2004 Virginia Rural Health Association's Best Practices Award, 2004 Virginia Governor's community Service and Volunteerism Administrative Award.

\section{Patients}

Most of the patients (61\%) seen at the Health Wagon do not have health insurance and report that they cannot afford health care (Table 1). Some patients who have insurance also come to the Health Wagon because they cannot afford the copayment charged at other institutions (Table 1).

The top nine diagnoses of the patients seen in 2009 were:

1. hypertension

2. diabetes

3. major depressive disorder

4. dyslipidemia (high cholesterol)

5. obesity

6. chronic obstructive pulmonary disease

7. hypothyroidism

8. gastro esophageal reflux disease

9. acute illnesses (eg upper respiratory tract infections, 'strep throat').

In 2009, a total of 157 clinics were provided and 2900 patients were seen (3165 patient encounters) in addition to 268 telemedicine specialty consults. In 2009, there was a $20 \%$ increase in patient volume compared with 2008 (3165 patients received comprehensive healthcare services). The average age of patients in 2009 was 43 years and 16\% of these were disabled (Table 2).

\section{Human and financial resources}

The work of the Health Wagon is possible due to the efforts of its board, staff, volunteers, organizational partners and funders. It is the recipient of Federal funding and receives financial support from a pharmaceutical company (Astra Zeneca Foundation) and private foundations and corporations.

Staff and board of directors: The Health Wagon is directed by a 13 member board of directors. The Health Wagon is headed by an executive director who is a doctoral trained certified family nurse practitioner. The Health Wagon employs two full-time certified family nurse practitioners, four nurses, two office staff, a social worker, data systems coordinator, program developer and a part-time clerk.

Volunteers: Volunteers include several community members (through the Experience Works Program), healthcare professionals (mostly nurses) and students (most are from University of Virginia at Charlotesville, Appalachian College of Pharmacy and East Tennessee State University on clinical rotation or practicum). Other volunteers help with mailing (newsletters, reports etc), filing, faxing, receptionist duties, and calling patients about specialty clinics. No recent data exist on volunteer hours but it is estimated that 2500 hours are donated by volunteers annually.

Organizational partners: In providing health care, the Health Wagon collaborates with many partners, including the University of Virginia Health Systems; Dickenson Community Hospital (which conducts most of patients' laboratory and diagnostic tests); Amerigroup; the Richmond Diocese of the Catholic Church; The American Breast Cancer Foundation; the United Breast Cancer Foundation; Appalachian College of Pharmacy (which conducts health education for patients on topics such as smoking and nutrition); East Tennessee State University; Mountain States Health System (provides specialist diabetology); and Lenowisco and Cumberland Health Districts. Other partners include Virginia Health Care Foundation, Virginia free clinic Association, Norton Community Hospital, Health Appalachia and University of Virginia Health System (Telemedicine). 
Table 1: Reasons (\%) given by patients for visiting the Health Wagon in 2009

\begin{tabular}{|l|c|}
\hline Reason & $\mathbf{\%}$ \\
\hline No insurance, cannot afford health care & 61 \\
\hline Have insurance, cannot afford co-payment & 10 \\
\hline Clinic convenience & 7 \\
\hline Other & 6 \\
\hline Need assistance with medications & 8 \\
\hline Care given by staff & 5 \\
\hline Another provider referred for medication/laboratory assistance & 2 \\
\hline No transportation & 1 \\
\hline
\end{tabular}

Table 2: The Health Wagon patients' demographics, 2009

\begin{tabular}{|c|c|}
\hline Demographic item & $\%$ \\
\hline Age $<18$ years & 9 \\
\hline \multicolumn{2}{|l|}{ Sex } \\
\hline Female & 71 \\
\hline Male & 29 \\
\hline \multicolumn{2}{|l|}{ Race } \\
\hline White & 97 \\
\hline Black/African American & 1 \\
\hline Asian & 1 \\
\hline Hispanic & 1 \\
\hline \multicolumn{2}{|l|}{ Marital status } \\
\hline Married & 48 \\
\hline Single & 27 \\
\hline Divorced & 13 \\
\hline Separated & 6 \\
\hline Widower & 5 \\
\hline \multicolumn{2}{|l|}{ Insurance status } \\
\hline No insurance & 72 \\
\hline Medicare & 10 \\
\hline Medicare part D & 3 \\
\hline Medicaid & 1 \\
\hline Private insurance & 1 \\
\hline \multicolumn{2}{|l|}{ Prescription drug coverage } \\
\hline No & 73 \\
\hline Yes & 27 \\
\hline \multicolumn{2}{|l|}{ Employed } \\
\hline No & 62 \\
\hline Yes & 38 \\
\hline \multicolumn{2}{|l|}{ Income level (\%) } \\
\hline $0-9,999$ & 36 \\
\hline $10,000-19,999$ & 34 \\
\hline $20,000-29,999$ & 16 \\
\hline $30,000-39,999$ & 10 \\
\hline$\geq 40,000$ & 4 \\
\hline Disabled & 16 \\
\hline
\end{tabular}


Donors and funders: In 2010, the Health Wagon's annual income was US\$779,985 excluding the value of volunteer time. While the Health Wagon conducts activities and special events to raise funds, regular funding comes from the following main sources:

1. Contributions/grants from private organizations/foundations/(eg a pharmaceutical company and corporations, and community hospitals)

2. Federal and state support/grants

3. Donations from patients, churches, civic organizations.

In $2010,76 \%(\$ 594,257)$ of total income came from federal and state support through the Health Resources and Services Administration (HRSA) and Bureau of Primary Health Care grants. Although only $\$ 1,306$ (in cash) was raised from patient donations in 2010, many patients also donate canned foods, fruit and vegetables in exchange for services.

\section{Healthcare services provided}

The Health Wagon provides mainly primary healthcare services, and health education that emphasizes disease prevention. The main healthcare services provided are:

- acute disease management (eg upper respiratory tract infections, sore throats)

- chronic disease management (eg hypertension, diabetes, high cholesterol)

- lab and diagnostic services

- medication assistance and Pharmacy Connect Program

- immunization programs

- wellness classes and health education

- dental and eye clinics

- diabetes outreach program

- cancer screenings

- $\quad$ specialty clinics (eg cardiac, diabetology, nephrology with renal ultrasound), pulmonology
- lung cancer early detection (chest X-ray)

- women's health.

- Cariovascular Outreach

In addition, The Health Wagon provides patients in need with walkers, canes, crutches, adult diapers and nutritional supplements through its Loan Closet for Medical Supplies program.

The Health Wagon also undertakes the following initiatives to promote health and enhance quality of life among the population it serves:

- Remote Area Medical (RAM) Health Expedition

- mobile clinic and health fairs

- linking patients with specialists at University of Virginia Health System via telemedicine

- Fixed clinics.

Remote Area Medical Health Expedition: In conjunction with the RAM Volunteer Corps, the Health Wagon spearheads the RAM Health Expedition in Wise county, Virginia annually. The RAM Health Expedition brings together healthcare providers to provide mainly eye, dental and medical care, including prescriptions at no cost to patients. The RAM Health Expedition attracts many people from the region and has set the US record for the number of patients seen in a three-day period (5683 patient encounters). In 2009, it provided over $\$ 2.2$ million in free care. The 5683 patients received:

- 2653 episodes of general medical care

- 1029 eye glasses with eye examinations, and 196 additional eye tests

- 1545 episodes of general dental care, 4893 extractions, 2113 fillings, 278 teeth cleaning, 1545 dental examinations only, 35 dentures

- 260 mammograms and 36 Pap smears

- 138 ear, nose and throat examinations, 364 audiotests, 126 hearing aids 
- 20 colposcopies, 10 colposcopies with biopsy, 9 endometrial biopsies and 4 loop electrosurgical excision procedures (LEEP)

- 50 sigmoidoscopies.

Over 1700 volunteers, most of whom are medical professionals, have contributed more than 20000 hours of donated time to the event from 2000 to 2009. The RAM health expedition has provided $\$ 10.5$ million in free care to 51535 patient encounters over 10 years (2000-2009) ${ }^{11}$.

Mobile clinics and health fairs: The mobile clinic is the primary means of the Health Wagon health care delivery. The (mobile) Health Wagon visits eight sites in Southwest Virginia's Buchanan, Dickenson, and Wise counties on weekly, biweekly and monthly bases. The Health Wagon also offers specialized mobile clinics, including mobile mammography clinic and lung cancer early detection. In addition, there is a cardiovascular and chronic obstructive pulmonary disease outreach program.

The health fairs, usually jointly coordinated by community and other partners (eg the Appalachian College of Pharmacy), are held at community centers and churches close to where patients live and work. In addition, The Health Wagon conducts health fairs in different communities at regular times using the mobile health clinic. At health fairs, comprehensive health care is provided that includes dental cleaning, screening, and health education. Health fairs are utilized to identify those at risk for health problems or with health problems. These identified patients are encouraged to establish as the Health Wagon patients if they wish.

Mobile mammography clinic: University of Virginia Health System and the Health Wagon combine to provide state of the art breast health screenings (digital mammograms) to its female patients, most of whom are uninsured or have no ready access to mammography services. Extensive case management services are provided to patients with abnormal mammograms and those who require follow up by collaborating partners such as the American Breast Cancer Foundation, the United Breast Cancer Foundation,
Lenowisco and Cumberland Plateau Health Districts and Mountain States Health System.

Lung Cancer Early Detection Program: The Health Wagon in conjunction with a pulmonologist (Dr Joe Smiddy) offers the Lung Cancer Early Detection Program using a mobile unit. Services provided to patients include free chest $\mathrm{X}$-rays, arterial blood gas tests, pulmonary function testing, medical examinations, and respiratory medications. The mobile unit has provided more than 1500 chest X-rays which contribute greatly to treating lung cancer. Education about smoking cessation is also routinely provided through this program.

Specialty clinics: In partnership with the Mountain States, University of Virginia Health System, the Health Wagon offers free endocrinology/diabetology clinics for its patients once each quarter. Patients can also consult a dietician and certified diabetes educator, and for many this is their only opportunity to see a specialist and receive formal diabetes education.

The Health Wagon patients also have access to specialists from University of Virginia Health System through the use of telemedicine technologies, thus eliminating the need for travel. Remote diagnosis via videoconferencing at no cost to patients is available from the Health Wagon administrative offices for most clinical specialties, such as psychiatry, dermatology, endocrine, neurology and orthopedics. In 2009 , a total of 268 such consultations were provided.

Fixed clinics: The Health Wagon also operates a walk-in clinic at a fixed location (Clintwood, Virginia) that provides all the services described. An additional stationary clinic was opened in Wise, Virginia in January, 2012.

\section{Operational challenges}

The Health Wagon faces a number of challenges in providing health care. First, available staff and resources are small compared with the need/demand for services. Second, given the operational location (a predominantly rural area), it is 
difficult for the organization to attract staff with specialized skills (eg healthcare professionals, information technology support and grant writers). Third, there are significant difficulties in obtaining electronic medical records in the mobile clinic. Finally, only a small proportion of patients make donations/contributions towards their care. Obtaining finances to sustain clinic operations has always been challenging.

\section{Conclusion}

The Health Wagon provides a wide range of comprehensive health services to marginalized, poor and disenfranchised patients living in the mountains of Southwest Virginia in Central Appalachia. The Health Wagon has established positive and working collaborations with other organizations and has been able to attract resources to carry out its work, which has broken a financial barrier to healthcare access for many and offers unique and profound opportunities to improve health and expand health care in Central Appalachia, USA.

\section{References}

1. Cleary KK. Disparities in health status along socioeconomic lines: is equal access enough? Acute Care Perspectives 2001; 10(4): 1, 3-5.

2. Smith LH, Holloman CH. Health status and access to health care services: a comparison between Ohio's rural non-Appalachian and Appalachian families. Family \& Community Health 2011; 34(2): 102110.
3. Cohen JJ. Disparities in health care: an overview. Academic Emergency Medicine 2003; 10(11): 1155-1160.

4. Meleis AI. Culturally competent scholarship: substance and rigor. Advances in Nursing Science 1996; 19(2): 1-16.

5. Appalachian Regional Commission. Economic assessment of Appalachia: an Appalachian regional development initiative report. Washington, DC: Appalachian Regional Commission, 2010.

6. Friedell GH, Linville LH, Hullet S. Cancer control in rural Appalachia. Cancer 1998; 83: 1868-1871.

7. Appalachian Ohio Healthy Living Task Force. Report to the Governor on addressing obesity in Appalachian Ohio: Final report. Athens, Ohio: Ohio University; 2006.

8. Yabroff KR, King JC, Mangan P, Washington KS, Yi B, Lawrence W (Eds). Disparities in cervical cancer outcomes in the rural United States. Reducing Health Disparities in High Cervical Cancer Mortality Regions. Corpus Christi, TX: National Cancer Institute, 2001.

9. Centers for Disease Control and Prevention. Cancer death rates Appalachia, 1994-1998. MMWR Morbidity and Mortality Weekly Report 2002; 51(24): 527-529.

10. Behringer B, Friedell GH. Appalachia: where place matters in health. Preventing Chronic Disease 2006; 3(4): 1-4.

11. The Health Wagon. Health Wagon 2009 Annual Report. Clintwood, VA: The Health Wagon, 2009. 